\title{
Competency-Based Training Program for International Students
}

\author{
Ana Azevedo ${ }^{1}$, Deborah Hurst ${ }^{1} \&$ Rocky Dwyer ${ }^{2}$ \\ ${ }^{1}$ Faculty of Business, Athabasca University, Alberta, Canada \\ ${ }^{2}$ CENTRUM Católica Pontificia Universidad Católica del Perú, Santiago de Surco, Lima, Perú \\ Correspondence: Ana Azevedo, Faculty of Business, Athabasca University, P.O. Box 194 STN MAIN, Parksville, \\ BC V9P 2G4, Canada. Tel: 1-780-257-2911. E-mail: ana.azevedo@fb.athabascau.ca
}

Received: December 12, 2014

Accepted: January 29, 2015

Online Published: February 25, 2015

doi:10.5539/ibr.v8n3p11

URL: http://dx.doi.org/10.5539/ibr.v8n3p11

\begin{abstract}
The purpose of this paper is to introduce a training program for developing the self-discovery and self-regulation competencies of international students. The paper combines literature review from global leadership, international education and related disciplines to advance a competency-based program that addresses a critical need for greater integration and retention of international students in their host countries. Research evidence from the literature review further suggested that key competencies such as self-awareness and self-regulation are critical for enabling the development of culturally intelligent behaviours. The program therefore introduces an initial phase of experiential learning activities in mindfulness and sense-making to foster the development of the foundational competence self-discovery. In addition, a second phase of entrepreneurial projects is designed to support individual growth in three self-regulation competencies: psychological flexibility, human sustainability and entrepreneurial thinking. The importance of this training program for the effective social integration and long-term retention of international students is discussed. Opportunities for future research are also outlined in the concluding section.
\end{abstract}

Keywords: competency development, cross-cultural adaptation, international students, training program

\section{Introduction}

The contribution of professional immigrants to economic growth and innovation has been widely recognized in academic literature. In the entrepreneurship literature, for example, there is evidence of a significant relationship between international migration and entrepreneurship, with different research studies showing immigrants as more likely to become entrepreneurs, as compared to non-immigrants; higher rates of entrepreneurship activity in geographic areas with high number of immigrants, especially highly educated immigrants; and immigrants outperforming non-immigrants among a sample of highly successful entrepreneurs (Baughn, Neupert, \& Sugheir, 2013; Dalziel, 2008). The interconnection of immigration, innovation and economic growth is further supported by evidence from country-specific studies, as well as expert opinions regarding the importance of immigration for future economic prosperity.

In Canada, professional immigrants are perceived as critically important to help fulfill current and future market skill gaps, sustain economic growth, foster innovation and increase global competitiveness (Downie, 2010; Eaton, 2013). According to industry experts and policy-makers, immigrants may have in fact already provided all of the expected growth in Canada' workforce in the future, due to the aging and shrinking of its population, as well as its low birth rate (Chipello \& Millman, 2005). In a recent report regarding the economic impact of international students in Canada, it was estimated that in 2010 the 218200 long-term international students spent in excess of $\$ 7.7$ billion in tuition, accommodation and discretionary spending; they also directly contributed to the creation of 81000 jobs and to the generation of $\$ 445$ million in government revenue (RKA Inc., 2012). International students represent one of the most important groups of skilled workers or professional immigrants, together with internationally trained workers.

In United States, Hanson (2012) claimed that high-skilled immigrants have significantly contributed to productivity growth over the past several decades, through creativity and innovations. In addition, Orrenius and Nicholson (2009) suggested that skilled immigrants were responsible for a large portion of job growth in a variety of occupations between 2003 and 2007, including nursing, computer and math-related occupations.

Similar claims regarding the importance of immigrants for economic prosperity can be made in other countries, 
such as within the European Union. In Germany, Campbell (2012) recently suggested that securing highly qualified immigrants will be critical for the country's long-term economic prosperity and that specific policies are needed to foster better social integration and tolerance. In a recent report from the Organization for Economic Cooperation and Development (OECD), it was suggested that immigration provided $40 \%$ of the total population growth within the OECD area during the period between 2001 and 2011, in spite of modest immigration flows during the global financial crisis of 2007-2008 (OECD, 2013a).

At a global level, researchers, consultants and company leaders have continued to discuss the difficult challenges associated with the scarcity of global talent, especially with respect to highly educated or highly skilled professionals (Beechler \& Woodward, 2009; Guthridge, Komm, \& Lawson, 2008; Halsberger \& Vaiman, 2013; World Economic Forum, 2011). Beechler and Woodward (2009) noted that the complex demands of globalization, the adoption of new technologies and the increasingly diverse workforces will likely intensify the already robust war on talent going forward; these forces will continue to fuel the need for skilled immigrants.

The recruitment and retention of professional immigrants can however be a significant challenge, considering difficulties in language and in adjusting to different cultural traditions, problems with host country's recognition of immigrants' academic credentials and international work experience, and the stressful and often emotionally charged experiences of cross-cultural adaptation (Bimrose \& McNair, 2011; Cohen, Arnold, \& O’Neill, 2011). In Canada, for example, Somerville and Walsworth (2009) suggested that highly skilled immigrants (economic class migrants) are vulnerable to poor economic integration, as evidenced by the higher unemployment rates, lower earnings (partly due to skill discounting, or the devaluation of immigrants' foreign education and international work experience) and overall declining of employment outcomes (while the lower mean earnings of previous immigrant cohorts quickly converged to those of Canadian-born workers with similar professional backgrounds, this is no longer the case in recent economic class migrants) (Somerville \& Walsworth, 2009). Although migration is far from a homogenous phenomenon, Bimrose and McNair (2011) suggested, drawing on the work of Savickas and his colleagues (Savickas, 1997; Savickas et al., 2009), that issues of adaptability and identity are central to all immigrants and therefore should be given priority in the context of their career development.

Considering the above challenges, individual countries are encouraged to adopt a long-term immigration strategy that includes strong investment and support of international education, so that professional immigrants can be integrated early in their career development process. In recognition of the potential of international students to contribute to future economic prosperity, a number of countries have already started to implement either comprehensive or targeted strategies for increasing international student recruitment (for example, Australia, Canada, UK, France and Germany) (Altbach \& Knight, 2011; Andrade, 2006). However, it is unclear how well existing international student support services are able to respond to their cross-cultural adjustment or 'acculturation' needs (Rienties et al., 2012). Acculturation can be described as “...the dual process of cultural and psychological change that takes place as a result of contact between two or more cultural groups and their individual members" (Berry, 2005, p. 698).

This paper introduces a competency-based training program that is aimed at promoting international students' effective cross-cultural adjustment by strengthening their inner capabilities in key areas such as adaptability/flexibility, well-being, growth, creativity and innovation. The training program proposed in this paper focuses on one foundational or core competence (self-discovery), since this type of competence can be considered fundamental in enabling the development of other cross-cultural competencies, and on three self-regulation competencies (psychological flexibility, human sustainability and entrepreneurial thinking), as they can additionally promote the development of behavioural competencies. Taken together, we believe that these competencies can support deep personal change, from the inside out (Jokinen, 2004; Thomas et al., 2008). This program is therefore not intended to comprehensively address the wide range of cross-cultural competencies that have been discussed in academic literature.

The novelty of this paper is threefold: first, it proposes self-discovery as an encompassing core competence that includes both mindfulness and sense-making capabilities; second, it advances a new training program based on a unique combination of experiential exercises to develop self-discovery and self-regulation, thereby shifting the existing focus of cross-training programs away from outcome variables (e.g., cross-cultural behaviours) and towards their antecedents and potential mediators; third, it applies the empirically established link between mindfulness and self-regulation to a new context, namely cross-cultural adaptation.

Our article is organized as follows. First, in the Background section, we describe the opportunities and challenges created by international education. Second, we review the literature in international education and 
global leadership to summarize the main competencies that are needed for effective cross-cultural adaptation. In this literature review section, we also define and discuss the critical importance of three self-regulation competencies for international students: Psychological flexibility, human sustainability and entrepreneurial thinking. Third, we introduce our training program by describing our foundational or core competence and our three self-regulation competencies and by proposing a number of experiential learning activities that are needed to promote their development. In addition, we distinguish between a self-discovery phase (composed of experiential learning activities in two different areas) and a self-regulation phase, which includes two entrepreneurial engagement projects. Fourth, we conclude our paper with a discussion of the importance of this competency-based program for effective social integration and long-term retention of international students. Opportunities for future research are further outlined in this final section.

\section{Background}

The decision to invest early and strongly in international education may help counteract some of the challenges experienced by professional immigrants. First of all, if international students decide to stay in a country after their graduation, they will not encounter the typical problem associated with a non-recognition of their academic credentials. Second, the global demand for international education is expected to continue growing exponentially in the future, from 4.1 million in 2010 to 7.2 million by 2025 (Canadian Bureau of International Education [CBIE], 2012), thus providing individual countries with many opportunities for successful international student recruitment and retention. Third, recent studies in selected countries seem to indicate that a good portion of international students have the intention to stay in the host country after their graduation. For example, results from an online survey study conducted by Corporate Research Associates, Inc. on behalf of the Association of Atlantic Universities in Canada (AAU) revealed that the desire to live in Canada after graduation was among the top three most important reasons in international students' decision to attend a Canadian University (AAU, 2013). This finding is consistent with results from a 2013 survey of 1509 international students from 25 universities and colleges in Canada, conducted by the Canadian Bureau of International Education, which revealed that almost half (46\%) of respondents planned to apply for permanent residency (CBIE, 2013).

These findings however cannot be completely generalised. Results from a recent survey of international students conducted by the Expert Council of German Foundations on Integration and Migration (SVR) showed that almost two-thirds of the 6200 international students currently enrolled at 25 universities in Germany, France, The United Kingdom, The Netherlands and Sweden were interested in staying in the host country after their graduation, but only a small percentage of those students $(12.5 \%)$ had intentions to stay for more than five years (ICEF Monitor, 2012). According to a study by Soon (2010), the decision to migrate permanently, delay the return to the home country (due to for example, additional study intentions or short-term work opportunities) or return to the home country immediately is affected by a number of factors, including the individual's initial intention to return to the home country after his/her graduation, home country perceptions variables (notably the perceived preference for the home country's lifestyle, the perception of ample opportunities for using newly acquired skills and knowledge at home, and the perception of strong family ties), the duration of stay in the host country (the longer an individual stays in the host country, the less likely he or she is to return home), as well as other education-related factors (level of the degree - doctoral students are less likely to return home, compared to non-doctoral students; type of discipline - students from health sciences and commerce are less likely to return home, compared to students from science and humanities). Soon's (2010) online study of 623 international students in New Zealand further concluded that demographic variables and other family-related variables (e.g., age, gender, years of work experience, marital status and family socioeconomic status) had no significant impact on the intended return timeframes (Soon, 2010). In addition, Soon (2010) reported that nearly half (46\%) of international students currently enrolled at two universities in New Zealand had no intention to return to their home countries. International students' decision to return home seems to be influenced by a complex set of push (home country) and pull (host country) factors; however, there is supporting evidence that a reasonably good portion of international students do show intention to stay in the host country after graduation, with varying degrees, depending on the specific sample of international students and their chosen country of study (Kim, Bankart, \& Isdell, 2011).

International education nonetheless poses its own set of challenges. Aside from academic difficulties related to, for example, language and communication issues as well as to "unfamiliar cultures of learning" (Hall \& Wai-Ching Sung, 2009, p. 54), international students often face poor social adjustment or integration in their local communities, both within and outside their campuses (Andrade, 2006). Studies of international students' social adjustment challenges frequently revealed feelings of stress, anxiety, depression, loneliness and homesickness; lack of friendships with domestic students (international students most often formed friendships 
with other international students); and experiences of discrimination (CBIE, 2013; Popadiuk \& Arthur, 2004; Rajapaksa \& Dundes, 2002). In a further review of various studies of international students' social adjustment, Andrade (2006) concluded that variables such as country of origin (and the extent of cultural dissimilarity), gender and number of years in school affected the degree of social adjustment of international students. However, these studies also suggested that international students seemed in general less satisfied with their social integration, as compared to their academic integration. This finding can be at least partially explained by the fact that international students spend considerable extra time and effort trying to adjust academically, thus leaving them with little time to engage in social activities and to invest in building social relationships (Lewthwaite, 1996).

While higher education institutions may be equipped to address some of the challenges in cross-cultural adaptation encountered by international students (via the provision of services such as student orientation, buddy system or peer program, professional counseling), a number of studies highlighted the reluctance of these students in seeking professional help (Sawir, Maginson, Deumert, Nyland, \& Ramia, 2008). In reviewing the literature, Popadiuk \& Arthur (2004) reported that many international students viewed professional counseling in a negative way (due to their cultural traditions and to stigmas associated with mental health and the perceived lack of personal competency) and would rather suffer alone and/or seek social support from family or close friends. The authors suggested a change in focus in the provision of services from health problems to health promotion and prevention and a new emphasis on the development of group-based educational programs for international students that address their specific needs, such as coping with cross-cultural shock, developing effective communication and other interpersonal skills, and improving self-help as well as study skills (Popadiuk $\&$ Arthur, 2004).

The competency-based training program advanced in this paper provides a direct answer to this call for a greater focus on health promotion and prevention and for the early delivery of targeted program initiatives specifically aimed at the international student population. In particular, we discuss in this paper how a training program designed to develop key self-development competencies in international students - self-discovery and self-regulation - can provide a strong foundation for increasing self-awareness and adaptability skills, for promoting sustainable well-being and learning, and for unleashing creativity and innovation, within the broad context of cross-cultural adaptation and personal transformation (Jokinen, 2004). The training program discussed in this paper also includes two distinct phases: A first phase focused on the development of the core or foundational competence of self-discovery and a second phase of entrepreneurial engagement projects, aimed at both strengthening the self-discovery competence learned during the first phase and of promoting the development of key self-regulation competencies (psychological flexibility, human sustainability and entrepreneurial thinking). We believe that this second phase can further provide opportunities for international students to connect and contribute to the local community, so that they can develop a sense of belonging (Sawir et al., 2008).

As a growing number of countries decide to invest in strategies to increase international student recruitment, there is widespread recognition that the benefits of international education go far beyond its positive economic impact to include other important benefits such as intercultural learning, greater understanding and appreciation of diversity, preparation of globally-oriented citizens and the promotion of foreign policy interests abroad (CBIE, 2013; Hudzik, 2011). In order to support the achievement of these goals, additional initiatives and programs are needed to promote better social integration of international students. Furthermore, the authors of this paper believe that effective social integration is critical for enhancing the prospects of international student retention, after their graduation. The acquisition of human capital (i.e., knowledge and skills) through education and work experience is strengthened by the acquisition of social capital (i.e., networks of social relationships) (Lin \& Huang, 2005; Szelenyi, 2003).

\section{Competencies Needed for Cross-Cultural Adaptation}

Zhou, Jindal-Snape, Topping and Todman (2008) provided a historical review on the development of theories of cross-cultural shock, a term that was originally proposed in 1960 by the anthropologist Kalervo Oberg in order to describe the way people react to unfamiliar places or cultures (Bochner, 2003). According to these authors, early studies on migration tended to focus on the negative aspects of interacting with another culture, in particular, the mental health challenges associated with this process. However, by the 1980 s a different view regarding the nature of the cross-cultural adaptation process had emerged, with theoretical perspectives focusing more strongly on social psychology and education, versus medicine. Three main theoretical perspectives emerged - stress and coping, culture learning and social identification - and with each of these perspectives, a set of intervention guidelines was proposed to develop stress management skills, including affective-based 
techniques to reduce anxiety, increase emotional resilience and self-efficacy (in the stress and coping approach); social skills, including behaviour-based interventions to increase knowledge of the host culture and the development of interpersonal skills, such as language and communication skills (in the culture learning approach); and self-esteem and inter-group harmony skills, including cognitive-based techniques to emphasize inter-group similarities, raise cultural awareness and cultural sensitivity, as well as to deepen the understanding and appreciation of cultural diversity (in the social identification approach) (Zhou et al., 2008). These perspectives have been described as complementary in nature and in fact have been integrated into a comprehensive ABC (Affective, Behavioural and Cognitive) model of Acculturation (Ward, Bochner, \& Furnham, 2001). The ABC model has the advantages of being comprehensive, process-oriented and dynamic (integrating characteristics of the person and the situation), but it is also complex in nature and difficult to study and to test the specific contribution of its individual components (Zhou et al., 2008). Nonetheless, one of the main contributions of the work by Ward and his colleagues was to suggest that the process of cross-cultural adaptation can be broadly described in terms of two main categories: psychological adjustment (related to the stress and coping approach) and sociocultural adjustment (related to the culture learning approach) (Searle \& Ward, 1990; Ward \& Kennedy, 1992). In the training program introduced in this paper, we address one core competence (self-discovery) and three self-regulation competencies (psychological flexibility, human sustainability and entrepreneurial thinking). We believe that taken together, these competencies will strongly support the development of both psychological and sociocultural adaptation.

In a review of the global leadership literature, Jokinen (2004) identified three main types or levels of global leadership competencies, defined by this author as "those universal qualities that enable individuals to perform their job outside their own national as well as organizational culture, no matter what their educational or ethnical background is, what functional area their job description represents, or what organization they come from" (Jokinen, 2004, p. 201). The first level is called "the core of global leadership competencies", because these are essential in the development of other characteristics or competencies. These core or fundamental competencies are: self-awareness (a person's in-depth understanding of himself/herself, including understanding of one's emotions, strengths and weaknesses, values, self-image, needs and drives), engagement in personal transformation (a person's commitment to ongoing development of personal knowledge and skills, including the desire to experience and learn new things, a positive and proactive approach to learning, openness to change and criticism, and the presence of strong achievement and mastery motives) and inquisitiveness (a person's curiosity and concern with context, including the motivation and willingness to face unfamiliar situations and to potentially confront new things, the desire to seek information, knowledge and feedback from many different sources to support personal development, and the willingness to question one's own knowledge) (Black, 2005; Jokinen, 2004).

The second level of global leadership competencies addresses what Jokinen (2004) describes as the "desired mental characteristics of global leaders" (p. 206) and it includes knowledge, skills, abilities and personal attributes that have been recognized as important for leaders working in a global context, such as optimism, self-regulation (herein broadly defined to include the ability to handle stress, to control moods and impulses, emotional stability, resilience, open-mindedness and self-efficacy), social judgment skills, empathy, motivation to work in an international context, cognitive complexity, and acceptance or tolerance of complexity and its contradictions (for example, by seeing opportunity in diversity and by using diversity to stimulate creativity).

Finally, Jokinen's (2004) third level is called "the behavioral level leadership competencies" (p. 208) and it addresses competencies that are related to performing specific or concrete actions, including social skills (interpersonal skills such as communication, persuasion, negotiation, conflict management, teambuilding, and capacity to motivate and align others to one single vision), networking skills (more formalized relationship management skills such as building and maintaining networks, partnerships or alliances, and building communities), knowledge (knowledge of tasks and related skills such as computer or technical skills, knowledge of the organization and key business issues, and knowledge of people and cultures, especially an understanding and appreciation of cultural differences) and experience (international work experience, personal experiences that provide opportunities for intercultural interaction).

Considering the critical importance of the "core global leadership competencies" in enabling the development of abilities and skills in the other two levels, in the training program advanced in this paper, we initially focus on this first level (phase one of the program). The authors will propose experiential exercises aimed at developing one core competence (self-discovery competence) that will specifically address the self-awareness, personal transformation and inquisitiveness components, as discussed and integrated in Jokinen's (2004) research. For the purpose of this paper, competencies are defined as "dynamic combination of knowledge, understanding, skills 
and abilities" (Azevedo et al., 2012, p. 26).

In addition, we will discuss how a training program that promotes the development of this core competence can significantly affect other competencies at the second level. In particular, the authors will examine the impact of the self-discovery competence on three other competencies: psychological flexibility (defined as "the ability to contact the present moment more fully as a conscious human being, and to either change or persist when doing so serves valued ends"; Hayes \& Strosahl, 2010, p. 5), human sustainability (herein defined by the concept of thriving, or the ability to sustain oneself through "the joint experience of vitality and learning"; Spreizer, Porath, \& Gibson, 2012, p. 155) and entrepreneurial thinking (defined as the ability to rely on "non-linear thinking style patterns as intuition, creativity, imagination, and optimism that support the consideration of novel ideas, as well as risk-taking and perseverance in the face of failure"; Vance, Groves, Gale, \& Hess, 2012, p. 128). We note that these three concepts also represent a "dynamic combination of knowledge, understanding, skills and abilities" (Azevedo et al., 2012, p. 26) and therefore can be accurately described as competencies. To exemplify, the concept of psychological flexibility includes knowledge and understanding of its underlying processes of mindfulness and acceptance (for example, the importance of contacting the present moment in a non-judgmental fashion), and of commitment and behavioural change (for example, the importance of aligning actions to core values), as well as the skills and related abilities needed to implement these principles and ideas into one's life.

The authors of this paper examined the impact of our core competence, self-discovery, on these three specific second level competencies (psychological flexibility, human sustainability and entrepreneurial thinking) for a few good reasons. First, these three competencies fall within the broader notion of self-regulation, which plays a crucial role in the cross-cultural adaptation process. Research on cultural intelligence (defined as "a system of interacting knowledge and skills, linked by cultural metacognition, that allows people to adapt to, select, and shape the cultural aspects of their environment", Thomas et al., 2008, p. 126) suggested that the development of "culturally intelligent behaviour" depends on a general process of "cultural metacognition" (Thomas et al., 2008, p. 127), which describes the knowledge and ability to monitor, regulate and control one's cognitive and affective states. Thus in the growing number of studies on cultural intelligence, self-regulation is given a central role (Creque \& Gooden, 2011; Li, Mobley, \& Kelly, 2013). The self-regulation processes discussed in the cultural intelligence literature however tend to be more focused on cognitive process ("thinking about the thinking") hence the name "metacognition"-while our self-regulation competencies come closer to other conceptualizations that emphasized open-mindedness, propensity to suspend judgment, tolerance for ambiguity, flexibility in meeting needs or behavioural flexibility, adaptive capacity, ability to handle stress or resilience, ability to control moods and impulses, and emotional stability (for a detailed review, see Jokinen, 2004). Second, these three self-regulation competencies seem to be inter-related. For example, a number of studies examining psychological flexibility within an organizational context showed that psychological flexibility was correlated with mental health, improved job performance, learning and workplace innovation (Bond \& Flaxman, 2006). We can further speculate that there are other inter-relationships among psychological flexibility, entrepreneurial thinking and human sustainability (or thriving), such as the potential influence of entrepreneurial thinking on an individual' sense of vitality and capacity to learn. Third, as suggested by Thomas et al. (2008), we believe that these three competencies can have a strong potential impact on the so-called third-level of behavioural competencies (for example, the development of culturally-sensitive social skills), because they address key self-regulation processes that support psychological adjustment and behavioural change.

Considering the importance of self-regulation competencies for the acquisition of cross-cultural behaviour, the training program introduced in this paper also includes a second phase of entrepreneurial projects (herein broadly conceived as any type of project that creates a new product, service or event that meets an existing need in the local community) which are intended to further promote their development in international students. To support this aim, we suggest the design and implementation of two entrepreneurial projects that allow the acquisition of knowledge and practical experience in each of the three self-regulation competencies. We recommend that each entrepreneurial project address two of the four topics - psychological flexibility, entrepreneurial thinking and the two aspects of human sustainability (i.e., vitality and learning) - so that the projects become truly complementary in nature.

Our training program therefore shifts the focus from the more overt or behavioural competencies to inner competencies at the first and second levels, which provide a strong foundation to facilitate the entire cross-cultural adaptation process (Jokinen, 2004; Thomas et al., 2008). We start with self-discovery, because we believe that this competence is essential for the development of other key cross-cultural competencies (Mendenhall, Arnardottir, Oddou, \& Burke, 2013). In addition, we further strengthen the development of three self-regulation competencies, considering their critical role in enabling the acquisition of culturally-sensitive 
behaviours (Li et al., 2013).

We believe that the self-development competencies examined in this paper can bring about personal transformation and growth from the inside out and thus empower international students to more effectively integrate in their social environments, in a way that allows them to keep their core cultural values and at the same time selectively adopt new behaviours from their new environments. Research by Berry and his colleagues has suggested that even though acculturation is not an homogeneous process (individuals adjust to other cultures in different ways), this type of integration acculturation strategy (when individuals combine cultural values and behaviours from both home and host cultures) is not only the preferred acculturation strategy of immigrant youth, but it is also the least stressful, as compared to assimilation (when individuals do not maintain their cultural identity), separation (when individuals avoid interactions with members of another culture and cultural identity is strongly preserved) or marginalization (when cultural identity is lost and there is also little interest in engaging in relationships with other cultural groups, for reasons such as feelings of discrimination or exclusion) (Berry, 2005, 2008)

Finally, we note that this paper introduces the theoretical foundation and key experiential learning activities included in the new training program and it is the first step in a larger research agenda which will seek to empirically examine the extent to which this type of cross-cultural training will actually promote the development of self-discovery and self-regulation competencies. Additional research may be needed to refine the training program, as well as to ascertain the role of each of the three self-regulation competencies as mediators in the relationship between self-discovery (our antecedent or independent variable) and psychological and socio-cultural adjustment (the outcomes or dependent variables) (Swagler \& Jome, 2005; Ward \& Kennedy, 1993).

\section{Competency-Based Training for Effective International Student Integration}

\subsection{Phase 1: Self-Discovery Competence}

In the first phase of our training program, we include a series of experiential exercises to develop self-discovery. We define self-discovery as a competence that includes the knowledge, understanding, skills and abilities that are needed in order to engage in self-exploration, self-reflection and identity re-construction within the context of cross-cultural adaptation (Jackson, 2005; Li, Hodgetts, \& Ho, 2010). Self-discovery is a critical or core cross-cultural competence because it addresses the self-awareness and self-reflection processes required to pay attention, ask questions, learn and nurture self-development (Mendenhall et al., 2013; Negi, Bender, Furman, Fowler, \& Prickett, 2010). As discussed in a number of different studies, self-awareness is one of the most critical components in the development of cross-cultural competence. For example, in summarising the extensive review conducted by Bird, Mendenhall, Stevens and Oddou (2010), Mendenhall et al. (2013) mentioned self-awareness as one of the so-called preeminent competencies that are consistently examined in the global leadership literature (Mendenhall et al., 2013, p. 437). Negi et al. (2010) further noted that it is not sufficient to learn about others' cultures and that specific cultural training should promote the development of self-awareness (Negi et al., 2010). In this paper, we take Goleman's view of self-awareness ("the on-going attention to inner states"; Goleman, 2005, p. 46), which this author explains as a type of introspective awareness that is equivalent to mindfulness, or "paying attention in a particular way: on purpose, in the present moment, and non-judgmentally" (Kabat-Zinn, 1994, p. 4). Similarly, Brown and Ryan (2003) described mindfulness as an "enhanced attention to and awareness of current experience or present reality" or simply as "open or receptive awareness and attention" (Brown \& Ryan, 2003, p. 822). Therefore, the first building block of our self-discovery competence is mindfulness.

The concept of mindfulness has been extensively researched in the psychology and business literatures. Brown and Ryan (2003) for example, discussed the role of mindfulness in self-regulation and well-being, suggesting that open awareness and attention can facilitate recognition of basic needs; help individuals to disengage from automatic and unhealthy thoughts and behaviours; and enhance happiness, due to greater clarity and vividness of experience. In the business literature, mindfulness is considered an important skill for leaders, because it reduces feelings of anxiety, increases their overall ability to cope with stress and further facilitates the development of emotional intelligence (Hede, 2010; Tan, 2012). Mindfulness has also been associated with ethical decision-making, increased insight and greater organizational effectiveness (La Forge, 2000; Ruedy \& Schweitzer, 2010; Weick \& Putnam, 2006). These findings are further supported by growing medical research evidence suggesting that mindfulness practice can significantly affect different regions of the brain associated with, for example, self-regulation and behavioural flexibility, stress-coping and resilience, tolerance, introspection and sense of self (Congleton, Holzel, \& Lazar, 2015). 
While there are a number of different experiential exercises or practices that can cultivate mindfulness (e.g., yoga and Tai chi; daily journaling of thoughts and emotions; "just noticing" type of exercises), mindful meditation is the most commonly studied and recommended (Davis \& Hayes, 2011; Hayes \& Strosahl, 2010; Tan, 2012). In mindful meditation, the person or practitioner is invited to direct attention to his/her breath, as a way of increasing contact with the present moment (Ruedy \& Schweitzer, 2010). This individual learns to simply notice the mind wandering in different directions and, with repeated practice, he/she becomes increasingly able to watch the thoughts and let them go, by returning the attention back to breathing. This type of mindful meditation allows individuals to develop a certain distance to their thoughts and feelings (thus decreasing reactivity and positively affecting emotional regulation) and to become increasingly attuned with the present moment (Davis \& Hayes, 2011; La Forge, 2000).

In our competency-based program, we recommend a daily practice of mindful meditation, starting with 5-7 minutes a day and then increasing it slowly until an optimal level is achieved, according to personal preference (this could vary from 15-20 minutes per day to longer practices of 30-45 minutes). As a starting point, we suggest a combination of short (5-7 minutes) meditation exercises, such as focusing on the breath, focusing on the body (for example, scanning different parts of the body, to identify sensations or tensions), focusing on the sounds of a bell (following the sound of a bell until it fades) and/or using a guided visualisation approach (for example, repeating a few sentences to develop loving-kindness, inner peace or compassion). The first author of this paper has been practicing meditation for more than two decades and has determined it helpful to mix different types of exercises, in order to support varied experiences. In addition to meditation, we recommend the silent practice of mindful nature walking, wherein a person is encouraged to walk slowly on a nature path and to focus his/her awareness on each and every step of the way. This kind of mindful movement complements well the sitting meditation exercises suggested above and could be a good alternative for individuals who are not committed to other physical activities (e.g., yoga) that have been linked to mindfulness (Kabat-Zinn, 1994; Shelov, Suchday, \& Friedberg, 2009).

The second building block of our self-discovery competence is sense-making. Sense-making can be defined simply as "a process of dealing with uncertainty" (Seiling \& Hinrichs, 2005, p. 84), which naturally occurs when there is a difference between what is expected and what is encountered (Weick, 1995). Although this process of meaning-making is typically associated with problem-solving activities - Klein, Moon and Hoffman (2006, p. 71) for example, described it as a "motivated, continuous effort to understand connections (which can be among people, places and events) in order to anticipate trajectories and act effectively" - it is also understood as a process that is a regular or normal part of work life, considering the complex and changing nature of organizational environments (Seiling \& Hinrichs, 2005). Within the context cross-cultural adaptation, we view sense-making as an important process in promoting self-discovery, because it allows individuals to search for feelings, thoughts, insights and new interpretations that help them attribute meaning and better understand their personal experiences in the world (Duffy, 1995).

In our training program, we propose the use of an expressive and self-reflective writing technique, proprioceptive writing, in order to encourage sense-making (Trichter-Metcalf \& Simon, 2002). According to Lengelle and Meijers (2014), expressive writing is focused on both the process of creating a coherent personal story and of transforming emotions, while self-reflective writing is focused on developing "an individual's ability to notice and observe patterns and engage more dialogically with one's life material" (Lengelle \& Meijers, 2014, p. 5). These authors further noted that writing for self-development is an important, self-directed learning method that allows students to construct their personal and career stories without the need for ongoing professional guidance.

Proprioceptive writing is a self-guided exercise or method originally developed by Trichter-Metcalf and Simon (2002) to enable individuals to express their thoughts and reflect on them. It is described as a "path to self-exploration and creativity" that helps to integrate emotion and intuition and to let one find "meaning through feeling" (Trichter-Metcalf \& Simon, 2002, p. xxxi). Even though this method shares some similarities with meditation (proprioceptive writing relies on a regular, disciplined practice, as discussed below; furthermore, it shares some of the same goals as in meditation, such as creating freedom or detachment from thoughts), the authors explained that the main difference is that in meditation, an individual tries to let go of his/her thoughts, while in proprioceptive writing, an individual tries to engage with the thoughts, in order to reflect on and eventually transcend them, by opening up to imagination and self-discovery (Trichter-Metcalf \& Simon, 2002).

We suggest that international students adopt the traditional 25-minute practice of 5 times per week, as described by Trichter-Metcalf and Simon (2002). In this practice, the individual is asked to find a quiet space or room, wherein he/she can remain alone and uninterrupted. In this quiet place, all that is needed is a comfortable chair, a 
table or desk (without computers, telephones or any other sources of distraction), plus a pen and some unlined white paper. To create a calm and sacred environment, the authors recommend to play Baroque music and also to light up a candle (this ritual of creating a sacred space is similar to meditation). In the beginning of the practice, the individual can ask a few self-exploration questions, such as: What is on my mind at this moment? Is there a feeling, event or memory that I wish to explore? Or is there a particular story that needs to be told?

In the writing process, there are only three rules to follow: First, "write what you hear" (try to imagine your thoughts as if they were spoken words and then write them down, exactly as you hear or "receive" them); second, "listen to what you write" (use focused or attentive listening, without judging or censoring); third, "be ready to ask the proprioceptive question" - What do I mean by ...? This probing question should be asked frequently, in order to provoke a deeper exploration of meaning; also, the question should be written down on paper, together with the answer, to allow for a short pause or the slowdown of the thinking process (Trichter-Metcalf \& Simon, 2002, pp. 32-35). Lengelle and Meijers (2014) provided the following example: If a student writes I am "...frustrated by my new boss", a proprioceptive question would be "What do I mean by frustrated by my new boss?" and the answer could be that "...he is impatient; he did not take time to explain what my role was; he treated me like a child" and so on (Lengelle \& Meijers, 2014, p. 60). This question can be asked as many times as a person wants to, whenever there is a feeling or a sense that there is something more to be told.

The product of this 25-minute writing process is entitled a "Write" and it should always be followed by a final, concluding section that includes four questions: "What thoughts were heard but not written?"; "How or what do I feel now?"; "What larger story is the "Write" a part of?"; and "What ideas came up for future "Writes"?" (Trichter-Metcalf \& Simon, 2002, pp. 39-41). The authors underscored that many personal revelations actually occur during this final section, so it is therefore considered as a very important part of the writing method.

We conclude the discussion on self-discovery competence by pointing out that when mindfulness and sense-making activities are practiced on a regular basis, international students can build a solid basis to gain personal insights and to promote deeper understanding and self-knowledge. In addition, as previously mentioned, the development of self-discovery competence can positively affect psychological flexibility, human sustainability and entrepreneurial thinking. To exemplify, mindfulness is perceived as a central practice needed in the development of key internal processes underlying psychological flexibility, including acceptance, cognitive defusion (diminishing or altering the "domination of verbal stimuli in the regulation of behavior"; Bond, Hayes, \& Barnes-Homes, 2006, p. 7), contact with the present moment (being present, or being able to experience a "continuous awareness of what is occurring now, and now, and now"; Hayes \& Strohsal, 2010, p. 43); and 'self as context' (or simply "contact with a transcendent sense of self"; Bond, Hayes, \& Barnes-Homes, 2006 , p. 10). We further expect that the practice of proprioceptive writing will strengthen these adaptability/flexibility benefits, given the invitation to "being present" and to developing focused attention and focused listening (Trichter-Metcalf \& Simon, 2002).

We also expect that self-discovery experiential exercises can positively impact human sustainability and entrepreneurial thinking. One of the key aspects of thriving (our central concept used to describe human sustainability) is the experience of vitality ("the sense that one is energized and feels alive"; Spreitzer, Porah, \& Gibson, 2012, p. 155). The second aspect is learning ("growing through new knowledge and skills"; Spreitzer et al., 2012, p. 155). As Spreitzer et al. (2012) explained, it is essential that individuals continuously remain attuned or mindful to their levels of vitality and learning, so that they are able to better self-regulate and change behavior, whenever needed. For example, when individuals feel stressed or fatigued, they can employ a number of individual strategies for energy renewal, such as taking more frequent breaks during work (or study), devoting time off from work during evenings and/or weekends to unwind and recharge their energy (for example, by engaging in relaxation activities and physical exercise) and making sure that they get enough sleep (Fritz, Lam, \& Spreitzer, 2011; Sonnentag, Binnewies, \& Mojza, 2008). Similarly, too much emphasis on learning, without appropriate time for recovery and restoration, can produce information overload and diminished mental performance. Therefore, by using self-discovery practices in mindfulness and sense-making, an individual is better able to develop key self-regulation competencies, such as human sustainability. This relationship is further supported by psychology studies which correlate mindfulness with self-regulation and well-being (for a detailed review, see Brown \& Ryan, 2003; Davis \& Hayes, 2011).

Finally, mindfulness and sense-making activities can also foster creativity, intuition and holistic thinking, which are all important aspects or dimensions of entrepreneurial thinking (Vance et al., 2012; Weick \& Putnam, 2006). For example, in reviewing the early history of the mindfulness construct in the business, psychology and educational literatures, Langer and Moldoveanu (2000) noted that mindfulness was positively associated with creativity in the workplace and with better use of creative solutions in a learning or educational context. These 
early findings are further supported by recent research, which suggests that mindfulness training may reduce "the influence of the past on present-moment experiences" (Ostafin \& Kassman, 2012, p. 1032) and increase intuition through greater attention to the body and the experience of emotions (Goleman, 2005; Tan, 2012). In addition, Ostafin and Kassman (2012) showed in a couple of different experimental studies that mindfulness (measured with the Mindful Attention Awareness Scale or MAAS; Brown \& Ryan, 2003) was positively correlated with insight problem-solving (measured by a combination of three unique problems - the prisoner's rope problem, the antique coin problem and the inverted steel pyramid problem, as per Schooler, Ohlssom, \& Brooks, 1993), but not significantly related to non-insight problems (also measured with a combination of two problems, as per Schooler, Ohlssom, \& Brooks, 1993 - the card problem and the criminal problem). Regarding sense-making, we agree with Drazin, Glynn and Kazanjian (1999) that creativity can best be understood as a process of engagement, wherein "an individual behaviorally, cognitively, and emotionally attempts to produce creative outcomes" (Drazin, Glynn, \& Kazanjian, 1999, p. 290). As explained by these authors, this process can essentially be viewed as a sense-making activity - i.e., individuals are confronted with equivocal events or problems and then they try to make sense of them by developing some type of meaning, so that they are able to identify creative or novel solutions. However, as Krueger (2007) explained within the context of entrepreneurship education, entrepreneurial actions can be traced all the way back to deep cognitive structures and beliefs or "assumptions that underpin our sense-making and decision-making" (Krueger, 2007, p. 124). Therefore, when an individual is confronted with the need to change their deep cognitive structures, which is the case during the cross-cultural adaptation process (from a cognitive perspective, national cultures can be understood as "shared cognitive structures" that are composed of categories or schemas; see for example Romney \& Moore, 1998; Shaw, 1990), it is necessary to encourage and nurture his/her self-reflective abilities, so that this person is able to advance his/her knowledge base by "confronting significant discrepancies and contradictions" (Krueger 2007, p. 125). We believe that the sense-making method proposed in this paper offers ample opportunities for focused attention and deeper self-reflection among international students. This connection between proprioceptive writing and creativity is supported by a number of personal accounts that were discussed in Trichter-Metcalf and Simon's book (2002). Thus, taken together, we expect that the two building blocks of our self-discovery competence - mindfulness and sense-making — can have a potentially strong influence on creativity, intuition and other aspects of entrepreneurial thinking.

The experiential activities proposed for phase 1 of our training program are summarised in Table 1 . We envision this first phase as ideally suitable for the second semester of a study program, since international students typically need the first semester term to get acquainted with their new academic life. The first program phase will include a 4-week online teaching module to help students learn about the basic aspects of mindfulness and proprioceptive writing (after this module, students will continue to practice on their own, for the remaining semester duration). In addition, phase 1 should conclude with an individual report, wherein international students will identify and discuss the main insights, challenges and lessons learned in their self-discovery process. We entitled our training program "Creating a new home inside yourself" to underscore the fact that one of the key outcomes of this program is to provide an inner space for international students where they feel safe to engage in self-exploration and self-development.

Table 1. Training program - creating a new home inside yourself

\begin{tabular}{lll}
\hline \multicolumn{1}{c}{ Phases } & \multicolumn{1}{c}{ Content } & \multicolumn{1}{c}{ Activities } \\
\hline Self-Discovery Competence & $\begin{array}{l}\text { Experiential exercises to } \\
\text { develop self-discovery }\end{array}$ & $\begin{array}{l}\text { Development of regular practice in mindfulness and } \\
\text { sense-making (mindful meditation; mindful nature walking; } \\
\text { proprioceptive writing) }\end{array}$ \\
Self-Regulation Competencies & $\begin{array}{l}\text { Entrepreneurial projects to } \\
\text { develop self-regulation }\end{array}$ & $\begin{array}{l}\text { Design and implementation of community engagement projects } \\
\text { (developing new product/ service/event; working within } \\
\text { multi-cultural teams) }\end{array}$ \\
\hline
\end{tabular}

\subsection{Phase 2: Self-Regulation Competencies}

In the second phase of our training program, we suggest the design and implementation of two entrepreneurial projects. We define an entrepreneurial project as any type of project that is developed on the basis of a new idea (for example, a new service, product, or event) that could potentially be implemented in the future, either with the creation of a new venture, or alternatively, within an existing company or local community. In this paper, we 
therefore take the broader view that an entrepreneurial project involves "producing something new, innovating; taking action to produce products, services or events that are valued in the community because they meet specific needs" (Government of Quebec, 2006, p. 28).

Considering that one of the primary goals of this phase is to allow further development of self-discovery competence, we recommend that phase 1 activities continue throughout the duration of phase 2 . This extended practice in mindfulness and sense-making activities will assist international students in strengthening and solidifying their process of self-discovery, so that it becomes a central aspect of their personal and professional lives. In addition, the entrepreneurial projects suggested in this phase will further promote international students' knowledge and practice in key self-regulation competencies that are directly affected by the core or foundational self-discovery competence. To support this aim, we propose that each of the two projects be designed to address a combination of two self-regulation competencies (psychological flexibility, entrepreneurial thinking, and the two aspects of human sustainability - i.e., vitality and learning). Thus, international students may, for example, choose to design any new product, service or event that will help a company increase the psychological flexibility and entrepreneurial thinking of its employees. Alternatively, they can focus on entrepreneurial thinking and the human sustainability aspect of learning (acquisition of knowledge and skills). The only requirement that we specify is that there should be no overlap in topics, so that the second project becomes truly complementary to the first. So, if international students choose as their first project to develop a new idea (for example, a new program or event) that promotes entrepreneurial thinking and learning within a specific organization, the second project should focus on psychological flexibility and the human sustainability aspect of vitality (an example could be a new consulting company that offers wellness programs that teach adaptability and energy management skills). While we realise that the complementary nature of these projects may reduce international students' opportunities to work with different teams in projects 1 and 2, this requirement will allow international students to acquire knowledge in each of the key self-regulation competencies identified in our study as critically important for cross-cultural adaptation.

Finally, the entrepreneurial projects proposed in this training phase can bring two important additional benefits to international students. First, these students will have the possibility to work in multi-cultural teams, which will help them start developing their social skills in key areas such as communication, active teamwork, active listening, and negotiation within a multi-cultural context. The project work will therefore not only assist international students to gain inter-cultural knowledge and understanding in a practical situation, but also to start learning about common barriers to multi-cultural team effectiveness, such as differences in the use of direct versus indirect communication, lack of familiarity with the different accents and different levels of fluency in the team's working language, team members' difficulties in dealing with different attitudes towards time and other decision-making norms (how the group arrives at decisions), as well as their challenges in learning and coping with distinct attitudes towards group dynamics and group leadership (e.g., different ways of handling team conflict; different attitudes and expectations regarding team leadership) (Breth, Befar, \& Kern, 2006). Second, since the entrepreneurial projects are designed to include a strong community involvement component, they can foster international students' engagement in their local community. To encourage this type of social engagement, we recommend that the new product, service or event should solve an existing need that was identified via conversations or interviews with members of the local community and that international students be encouraged to develop this new idea with the goal of delivering a product/service/event that could potentially be adopted by members of the local community (i.e., the project may conclude with a "minimum viable product" or "minimum viable service" containing key basic features that could subsequently be tested and improved, on the basis of feedback from potential customers; Ries, 2011). The design and implementation of these projects will thus bring international students in close contact with a variety of community stakeholders, such as companies, government agencies, universities etc. International students' involvement in the two entrepreneurial projects could consequently increase their social capital as well as their feelings of belonging (Belkhodja \& Esses, 2013).

Regarding the duration of phase 2, we suggest that each of the entrepreneurial projects be carried out within one semester, so that the entire phase 2 is completed within one academic year. This one-year timeframe should give international students sufficient time to: conduct literature review on their respective topics, generate a list of potential ideas and interview topics, and to meet with community members to discuss and evaluate their specific needs. After the new project idea or concept has been defined, international students will work together within their respective groups to develop this new concept into a final product/service/event. We further suggest that the entrepreneurial projects be completed with a final group presentation to the rest of the class. Also, international students should submit an individual written report discussing their key personal learnings related to their project work and examining how their self-discovery activities supported them in their project work. Higher education 
institutions may choose to offer a certificate of completion in "Global Leadership, Wellness and Entrepreneurial Thinking" in order to encourage international students to remain engaged throughout the entire program duration of three semesters.

We conclude this discussion of phase 2 of our training program by mentioning that although phase 2 activities will help promote understanding and development of self-regulation competencies, future coursework and/or additional experience with applied projects in the areas of psychological flexibility, human sustainability and entrepreneurial thinking may further enhance competency development in these areas. For example, specific courses in entrepreneurship, coupled with applied projects in service learning or problem-based learning, can bring deeper knowledge and acquisition of entrepreneurial skills (Krueger, 2007). Similarly, international students' engagement in coursework and applied projects related to specific aspects of human sustainability (such as energy management or stress management) or psychological flexibility (for example, life coaching or visionary thinking) can strengthen competency development in these areas. Table 1 provides a summary of phase 2 activities.

\section{Conclusion}

There is widespread recognition of the importance of professional immigrants to the future economic prosperity and innovation of different countries, as discussed in a number of research studies reviewed in this paper (Baughn et al., 2013; Downie, 2010; Hanson, 2012; OECD, 2013a). Additional research has also shown that international students - one of the important groups of highly qualified or skilled immigrants, together with internationally trained workers - can significantly contribute to economic development during their time of study (RKA Inc., 2012). Considering international students' perceived talent and potential to stay in their host country after graduation, a growing number of countries around the world are embracing comprehensive international student recruitment strategies, as a means to counteract the effects of an aging and shrinking workforce (Altbach \& Knight, 2011; Andrade, 2006; Chipello \& Millman, 2005; Eaton, 2013). However, as recently suggested by Belkhodja and Esses (2013), within the context of the Canadian labour market, the actual contribution of international students to society depends on their appropriate or effective social and economic integration. As noted by these authors, "acculturation is always a key obstacle" (Belkhodja \& Esses, 2013, p. 16), which is hindered by the lack of understanding of cross-cultural differences between one's country of origin and the host country and by the often insufficient command of the host country's language. Belkhodja and Esses (2013) further mentioned that while international education is not a recent phenomenon for most OECD countries, only since the early 2000s there has been a significant shift in the way that international students are perceived and treated by their host country's government and society. To be sure, international students in the past few decades were perceived primarily as a source of revenue for higher education institutions; only in recent years they were recognized as perfect or "ideal candidates for immigration" (Belkhodja \& Esses, 2013, p. 3). Part of this shift is of course due to the extraordinary growth in international education. According to a recent report from OECD (2013b), there were close to 4.3 million studying abroad in 2012, which indicated a $70 \%$ growth in international student enrollment, as compared to 2000 (OECD, 2013b). Additional contributing factors that were discussed in our paper include: global demographic trends (aging of the workforce) leading to current and expected future labour market shortages; the empirical evidence supporting the interconnection among immigration, innovation and economic growth; the specific challenges of integrating internationally trained workers (for example, the problem with recognition of academic qualifications); and the intention of international students to stay in the host country after graduation, at varying degrees (AAU, 2013; Kim et al., 2011; Soon, 2010).

However, we have argued in this paper that the effective integration of international students is an important precondition for their future retention. Studies in international education showed that while academic integration challenges were present, social adjustment challenges prevailed (evidenced by, for example, international students' frequent feelings of stress, anxiety, depression, loneliness, homesickness, as well as experiences of discrimination; also, in general, international students reported a lack of friendships with domestic students) (Andrade, 2006; CBIE, 2013; Rajapaksa \& Dundes, 2002). In addition, although institutions of higher education have developed professional services to support international student integration (international student centres have typically offered a combination of services, such as student orientation, buddy system or peer program; professional advice on issues related to immigration, student work permit or taxation; professional counseling), Popadiuk and Arthur (2004) suggested that international students remain reluctant to use any type of professional counseling and actually prefer to either "suffer alone" or seek the support of family and close friends. These authors proposed the development of early intervention programs that are specifically tailored to international students' needs.

After extensive literature review in global leadership, international education and related disciplines, the authors 
of this paper introduced a competency-based training program that is intended to simplify the journey for international students, by "building capacity within" (developing inner competencies that are critical for cross-cultural adaptation). We realised that most of the focus of existing cross-cultural adaptation research and practice has been placed on the more overt or behavioural competencies (e.g., language and other social skills; Jokinen, 2004), probably because these competencies are urgently needed in order to provide international students with a good level of functioning within a new social environment.

Nonetheless, there is sufficient empirical evidence suggesting that these behavioural or third level competencies cannot be effectively learned without the development of key inner competencies at the first and second levels, such as self-awareness and self-regulation competencies (Jokinen, 2004). A growing number of research studies in culture intelligence, international management and global leadership provided additional evidence in support of Jokinen's (2004) central argument that the development of these competencies is fundamental in facilitating the development of higher level competencies (Negi et al., 2010; Mendenhall et al., 2013; Thomas et al., 2008).

The competency-based program advanced in this paper therefore focuses on one key competence at the first level (self-discovery) and three self-regulation competencies at the second level (psychological flexibility, human sustainability and entrepreneurial thinking). Our training program combines a number of experiential activities in two separate phases (experiential exercises to foster self-discovery in the first phase; entrepreneurial projects to strengthen the connection between self-discovery and self-regulation processes and to further promote the development of three self-regulation competencies in the second phase) and it is designed to give international students sufficient amount of time to experiment, reflect and integrate these practices into their lives. In addition, considering the nature of the entrepreneurial projects proposed in phase 2, international students will have the opportunity to gain invaluable inter-cultural knowledge and understanding (from working within multi-cultural teams) and to proactively engage in their local communities. We believe that by helping international students "build capacity within", and by enhancing their prospects of acquiring social capital (Lin \& Huang, 2005), this program will significantly contribute to their effective integration and retention in their host communities.

Future research may examine the level of impact of our training program on self-discovery and on each of the three self-regulation competencies. Given the novelty of this program, it would be important to investigate to what extent phase 1 activities actually contribute to the mindfulness and sense-making processes underpinning the self-discovery competence. In addition, future studies may assess the specific effect of our training program on the three self-regulation competencies - psychological flexibility, human sustainability and entrepreneurial thinking - as a consequence of the extended practice with self-discovery exercises and the implementation of the two entrepreneurial projects. Further research will also be needed to verify the role of these self-regulation competencies as potential mediators between self-discovery and key outcome variables such as psychological and socio-cultural adjustment. Finally, it would be interesting to compare international students from different countries to identify potentially distinct patterns in the way that they respond to each of the program activities.

To conclude, we believe that this program can serve as a critical resource to help empower international students in their cross-cultural adaptation process. The training program described in this paper can help establish a solid foundation for international students' personal transformation from the inside out, so that they are able to effectively cope with the challenging demands of cross-cultural adaptation. This program may be supplemented by study courses and/or applied projects in key areas such adaptability/flexibility, entrepreneurial thinking, wellness and intercultural competence. With a strong foundation in key competencies developed early on, international students will be better equipped to meaningfully engage in their social environments and to continue to make progress in their personal and professional lives.

\section{References}

AAUC. (2013). Immigration and universities in Atlantic Canada: A marriage made in heaven. Retrieved April 8, 2014 , from http://www.atlanticuniversities.ca/blog/public-policy-paper-series/immigration-and-universities-atlantic-can ada-marriage-made-heaven

Altbach, P. G., \& Knight, J. (2007). The internationalization of higher education: Motivations and realities. Journal of Studies in Higher Education, 11(3-4), 290-305.

Andrade, M. S. (2006). International students in English-speaking universities. Journal of Research in International Education, 5(2), 131-154. http://dx.doi.org/10.1177/1475240906065589

Azevedo, A., Omerzel, D. G., Andrews, J., Higson, H., Caballero, A., \& Frech, B. (2012). Satisfaction with 
knowledge and competencies: A multi-country study of employers and business graduates. American Journal of Economics and Business Administration, $4(1), \quad$ 23-39. http://dx.doi.org/10.3844/ajebasp.2012.23.39

Baughn, C. C., Neupert, K. E., \& Sugheir, J. S. (2013). Domestic migration and new business creation in the United States. Journal of Small Business \& Entrepreneurship, 26(1), 1-14. http://dx.doi.org/10.1080/08276331.2012.761799

Beechler, S., \& Woodward, I. C. (2009). The global "war for talent”. Journal of International Management, 15, 273-285. http://dx.doi.org/10.1016/j.intman.2009.01.002

Belkhodja, C., \& Esses, V. (2013). Improving the assessment of international students' contribution to Canadian society. $\quad$ Retrieved from http://p2pcanada.ca/wp-content/uploads/2014/02/International-Students-Contribution-to-Canadian-Society. pdf

Berry, J. W. (2005). Acculturation: Living successfully in two cultures. International Journal of Intercultural Relations, 29(6), 697-712. http://dx.doi.org/10.1016/j.ijintrel.2005.07.013

Berry, J. W. (2008). Globalisation and acculturation. International Journal of Intercultural Relations, 32(4), 328-336. http://dx.doi.org/10.1016/j.ijintrel.2008.04.001

Bimrose, J., \& McNair, S. (2011). Career support for migrants: Transformation or adaptation? Journal of Vocational Behavior, 78(3), 325-333. http://dx.doi.org/10.1016/j.jvb.2011.03.012

Bird, A., Mendenhall, M., Stevens, M. J., \& Oddou, G. (2010). Defining the content domain of intercultural competence for global leaders. Journal of Managerial Psychology, 25(8), 810-828. http://dx.doi.org/10.1108/02683941011089107

Black, J. S. (2005). The mindset of global leaders: Inquisitiveness and duality. Advances in Global Leadership, 4 , 181-200. http://dx.doi.org/10.1016/S1535-1203(06)04013-5

Bochner, S. (2003). Culture shock due to contact with unfamiliar cultures. Online Readings in Psychology and Culture, 8(1), 7. http://dx.doi.org/10.9707/2307-0919.1073

Bond, F. W., \& Flaxman, P. E. (2006). The ability of psychological flexibility and job control to predict learning, job performance, and mental health. Journal of Organizational Behavior Management, 26(1-2), 113-130. http://dx.doi.org/10.1300/J075v26n01_05

Bond, F. W., Hayes, S. C., \& Barnes-Holmes, D. (2006). Psychological flexibility, ACT, and organizational behavior. Journal of Organizational Behavior Management, 26(1-2), $25-54$. http://dx.doi.org/10.1300/J075v26n01_02

Brett, J., Behfar, K., \& Kern, M. C. (2006). Managing multicultural teams. Harvard Business Review, 84(11), 84-91.

Brown, K. W., \& Ryan, R. M. (2003). The benefits of being present: Mindfulness and its role in psychological well-being. Journal of Personality and Social Psychology, 84(4), 822-848. http://dx.doi.org/10.1037/0022-3514.84.4.822

Campbell, L. E. (2012). Multikulti ist Doch'Ne Erfolgreiche Realitat: Why tolerance is vital for German economic growth. Boston College International \& Comparative Law Review, 35(2), 449-480.

CBIE. (2012). A world of learning: Canada's performance and potential in international education. Ottawa: Canadian Bureau of International Education.

CBIE. (2013). A world of learning: Canada's performance and potential in international education. Ottawa: Canadian Bureau of International Education.

Chipello, C. J., \& Millman, J. (2005, May 23). Canada's open door to immigrants is seen as crucial for growth. Wall Street Journal. Retrieved from http://online.wsj.com/news/articles/SB111680576179640256

Cohen, L., Arnold, J., \& O'Neill, M. (2011). Migration: Vocational perspectives on a complex and diverse transition. Journal of Vocational Behavior, 78(3), 321-324. http://dx.doi.org/10.1016/j.jvb.2011.03.011

Congleton, C., Holzel, B. K., \& Lazar, S. W. (2015, January 8). Mindfulness can literally change your brain. Retrieved from https://hbr.org/2015/01/mindfulness-can-literally-change-your-brain

Creque, C. A., \& Gooden, D. J. (2011). Cultural intelligence and global business competencies: A framework for organizational effectiveness in the global marketplace. International Journal of Management \& Information 
Systems (IJMIS), 15(4), 141-146.

Dalziel, M. (2008). Immigrants as extraordinarily successful entrepreneurs: A pilot study of the Canadian experience. Journal of Small Business \& Entrepreneurship, 21(1), 23-36. http://dx.doi.org/10.1080/08276331.2008.10593411

Davis, D. M., \& Hayes, J. A. (2011). What are the benefits of mindfulness? A practice review of psychotherapy-related research. Psychotherapy, 48(2), 198-208. http://dx.doi.org/10.1037/a0022062

Downie, M. (2010). Immigrants as innovators: Boosting Canada's global competitiveness. Ottawa: Conference Board of Canada.

Drazin, R., Glynn, M. A., \& Kazanjian, R. K. (1999). Multilevel theorizing about creativity in organizations: A sensemaking perspective. Academy of Management Review, 24(2), 286-307.

Duffy, M. (1995). Sensemaking in classroom conversations. In I. Maso, P. A. Atkinson, S. Delamont \& J. C. Verhoeven (Eds.), Openness in research: The tension between self and other (pp. 119-132). Assen: Van Gorcum.

Eaton, M. (2013, April 23). Employers must take proactive approach to integrating immigrants. National Post. Retrieved from http://business.financialpost.com/2013/04/23/why-canadian-employers-must-integrate-immigrants-into-theworkforce/

Fritz, C., Lam, C. F., \& Spreitzer, G. M. (2011). It's the little things that matter: An examination of knowledge workers' energy management. The Academy of Management Perspectives, 25(3), 28-39. http://dx.doi.org/10.5465/AMP.2011.63886528

Globe and Mail. (2012, May 2). Rethinking Immigration: The case for the 400,000 solution. Retrieved from http://www.theglobeandmail.com/news/national/time-to-lead/rethinking-immigration-the-case-for-the-4000 00-solution/article4170229/

Goleman, D. (2005). Emotional intelligence (10th ed.). New York: Bantam Dell.

Government of Quebec. (2007). Introduction to entrepreneurial culture: Project development guide for teachers. Retrieved from http://www.inforoutefpt.org/mse/documents/guidemesure_ang_compl.pdf

Guthridge, M., Komm, A. B., \& Lawson, E. (2008). Making talent a strategic priority. McKinsey Quarterly, 1(1), 49-59.

Hanson, G. (2012). Immigration and economic growth. Cato Journal, 32(1), 25-34.

Haslberger, A., \& Vaiman, V. (2013). Self-initiated expatriates: A neglected source of global talent flow. In V. Vaiman \& A. Halsberger (Eds.), Talent management of self-initiated expatriates-A neglected source of global talent (pp. 1-15). Basingstoke: Palgrave Macmillan. http://dx.doi.org/10.1057/9780230392809.0005

Hayes, S. C., \& Strosahl, K. D. (2010). A Practical guide to acceptance and commitment therapy. New York: Springer.

Hede, A. (2010). The dynamics of mindfulness in managing emotions and stress. Journal of Management Development, 29(1), 94-110. http://dx.doi.org/10.1108/02621711011009090

Hudzik, J. K. (2011). Comprehensive internationalization: From concept to action. Washington, D.C.: Association of International Educators.

ICEF Monitor. (2012, February 22). European survey reveals intentions of international students, compares legislation. Retrieved from http://monitor.icef.com/2012/05/european-survey-reveals-intentions-of-international-students-compares-legi slation

Jackson, T. A. (2005). To thine own self be true: Self-discovery, diversity, and pre-service teachers. Reaching Through Teaching, XVII(1), 5-13.

Jokinen, T. (2004). Global leadership competencies: a review and discussion. Journal of European Industrial Training, 29(3), 199-216. http://dx.doi.org/10.1108/03090590510591085

Kabat-Zinn, J. (1994). Wherever you go, there you are. New York: Hyperion.

Kim, D., Bankart, C. A., \& Isdell, L. (2011). International doctorates: trends analysis on their decision to stay in US. Higher Education, 62(2), 141-161. http://dx.doi.org/10.1007/s10734-010-9371-1 
Klein, G., Moon, B. M., \& Hoffman, R. R. (2006). Making sense of sensemaking 1: Alternative perspectives. IEEE Intelligent Systems, 21(4), 70-73. http://dx.doi.org/10.1109/MIS.2006.75

Krueger, N. F. (2007). What lies beneath? The experiential essence of entrepreneurial thinking. Entrepreneurship Theory and Practice, 31(1), 123-138. http://dx.doi.org/10.1111/j.1540-6520.2007.00166.x

La Forge, P. G. (2000). Four steps to a fundamental ethical vision through meditation. Journal of Business Ethics, 28(1), 25-34. http://dx.doi.org/10.1023/A:1006269113147

Langer, E. J., \& Moldoveanu, M. (2000). The construct of mindfulness. Journal of Social Issues, 56(1), 1-9. http://dx.doi.org/10.1111/0022-4537.00148

Lengelle, R., \& Meijers, F. (2014). Narrative identity: Writing the self in career learning. British Journal of Guidance \& Counselling, 42(1), 52-72. http://dx.doi.org/10.1080/03069885.2013.816837

Lewthwaite, M. (1996). A study of international students' perspectives on cross-cultural adaptation. International Journal for the Advancement of Counselling, 19(2), 167-185. http://dx.doi.org/10.1007/BF00114787

Li, M., Mobley, W., \& Kelly, A. (2012). When do global leaders learn best to develop cultural intelligence? An investigation of the moderating role of experiential learning style. Academy of Management Learning \& Education, 12(1), 32-50. http://dx.doi.org/10.5465/amle.2011.0014

Li, W. W., Hodgetts, D., \& Ho, E. (2010). Gardens, transitions and identity reconstruction among older Chinese immigrants to New Zealand. Journal of Health Psychology, 15(5), 786-796. http://dx.doi.org/10.1177/1359105310368179

Lin, S. C., \& Huang, Y. M. (2005). The role of social capital in the relationship between human capital and career mobility: Moderator or mediator? Journal of Intellectual Capital, 6(2), 191-205. http://dx.doi.org/10.1108/14691930510592799

Mendenhall, M., Arnardottir, A., Oddou, G., \& Burke, L. (2013). Developing cross-cultural competencies in management education via cognitive-behavior therapy. Academy of Management Learning \& Education, 12(3), 436-451. http://dx.doi.org/10.5465/amle.2012.0237

Negi, N. J., Bender, K. A., Furman, R., Fowler, D. N., \& Prickett, J. C. (2010). Enhancing self-awareness: A practical strategy to train culturally responsive social work students. Advances in Social Work, 11(2), 223-234.

OECD. (2013a). International migration outlook 2013. Retrieved from http://www.oecdepublishing.org/multilingual-summaries/migr_outlook-2013-sum/pdf/migr_outlook-2013-s um-en.pdf

OECD. (2013b). How many students study abroad and where do they go? Education at a Glance 2013: Highlights (OECD Publishing). http://dx.doi.org/10.1787/eag_highlights-2013-12-en

Orrenius, P. M., \& Nicholson, M. (2009). Immigrants in the U.S. economy: A host-country perspective. Journal of Business Strategies, 26(1), 35-53.

Ostafin, B. D., \& Kassman, K. T. (2012). Stepping out of history: Mindfulness improves insight problem solving. Consciousness and Cognition, 21(2), 1031-1036. http://dx.doi.org/10.1016/j.concog.2012.02.014

Popadiuk, N., \& Arthur, N. (2004). Counseling international students in Canadian schools. International Journal $\begin{array}{llll}\text { for the Advancement of } & \text { Counselling, 26(2), }\end{array}$ http://dx.doi.org/10.1023/B:ADCO.0000027426.05819.44

Rajapaksa, S., \& Dundes, L. (2002). It's a long way home: International student adjustment to living in the United States. Journal of College Student Retention: Research, Theory and Practice, 4(1), 15-28. http://dx.doi.org/10.2190/5HCY-U2Q9-KVGL-8M3K

Rienties, B., Beausaert, S., Grohnert, T., Niemantsverdriet, S., \& Kommers, P. (2012). Understanding academic performance of international students: The role of ethnicity, academic and social integration. Higher Education, 63(6), 685-700. http://dx.doi.org/10.1007/s10734-011-9468-1

Ries, E. (2011). The Lean startup: How today's entrepreneurs use continuous innovation to create radically successful businesses. New York: Crown Publishing.

RKA, Inc. (2012). Economic Impact of international education in Canada - An update final report. Ottawa: DFAIT.

Romney, A. K., \& Moore, C. C. (1998). Toward a theory of culture as shared cognitive structures. Ethos, 26(3), 


\section{4-337. http://dx.doi.org/10.1525/eth.1998.26.3.314}

Ruedy, N. E., \& Schweitzer, M. E. (2010). In the moment: The effect of mindfulness on ethical decision making. Journal of Business Ethics, 95(1), 73-87. http://dx.doi.org/10.1007/s10551-011-0796-y

Savickas, M. L. (1997). Constructivist career counseling: Models and methods. Advances in Personal Construct Psychology, 4(2), 149-182.

Savickas, M. L., Nota, L., Rossier, J., Dauwalder, J. P., Duarte, M. E., Guichard, J., Soresi, S., Van Esbroeck, R., \& Van Vianen, A. E. (2009). Life designing: A paradigm for career construction in the 21 st century. Journal of Vocational Behavior, 75(3), 239-250. http://dx.doi.org/10.1016/j.jvb.2009.04.004

Sawir, E., Marginson, S., Deumert, A., Nyland, C., \& Ramia, G. (2008). Loneliness and international students: An Australian study. Journal of Studies in International Education, 12(2), 148-180. http://dx.doi.org/10.1177/1028315307299699

Schooler, J. W., Ohlsson, S., \& Brooks, K. (1993). Thoughts beyond words: When language overshadows insight. Journal of Experimental Psychology: $\quad$ General, $162-193$. http://dx.doi.org/10.1037/0096-3445.122.2.166

Searle, W., \& Ward, C. (1990). The prediction of psychological and sociocultural adjustment during cross-cultural transitions. International Journal of Intercultural Relations, 14(4), 449-464. http://dx.doi.org/10.1016/0147-1767(90)90030-Z

Seiling, J., \& Hinrichs, J. (2005). Mindfulness and constructive accountability as critical elements of effective sensemaking: A new imperative for leaders as sensemanagers. Organization Development Journal, 23(3), 82-88.

Shaw, J. B. (1990). A cognitive categorization model for the study of intercultural management. Academy of Management Review, 15(4), 626-645.

Shelov, D. V., Suchday, S., \& Friedberg, J. P. (2009). A pilot study measuring the impact of yoga on the trait of mindfulness. Behavioural and Cognitive Psychotherapy, 37(5), 595-598. http://dx.doi.org/10.1017/S1352465809990361

Somerville, K., \& Walsworth, S. (2009). Vulnerabilities of highly skilled immigrants in Canada and the United States. American Review of Canadian Studies, 39(2), 147-161. http://dx.doi.org/10.1080/02722010902848169

Sonnentag, S., Binnewies, C., \& Mojza, E. J. (2008). Did you have a nice evening? A day-level study on recovery experiences, sleep, and affect. Journal of Applied Psychology, 93(3), 674-684. http://dx.doi.org/10.1037/0021-9010.93.3.674

Soon, J. J. (2010). When do students intend to return? Determinants of students' return intentions using a multinomial logit model. International Journal of Business and Society, 11(1), 17-32.

Spreitzer, G., Porath, C. L., \& Gibson, C. B. (2012). Toward human sustainability: How to enable more thriving at work. Organizational Dynamics, 41(2), 155-162. http://dx.doi.org/10.1016/j.orgdyn.2012.01.009

Swagler, M. A., \& Jome, L. M. (2005). The effects of personality and acculturation on the adjustment of North American sojourners in Taiwan. Journal of Counseling Psychology, 52(4), 527-536. http://dx.doi.org/10.1037/0022-0167.52.4.527

Szelenyi, K. (2003). Explaining the migration and settlement of foreign graduate students: Global integration theory and the theory of cumulative causation.

Tan, C. M. (2012). Search inside yourself: The unexpected path to achieving success, happiness (and World Peace). New York: HarperCollins Publishers.

Thomas, D. C., Elron, E., Stahl, G., Ekelund, B. Z., Ravlin, E. C., Cerdin, J. L., ... Lazarova, M. B. (2008). Cultural intelligence domain and assessment. International Journal of Cross Cultural Management, 8(2), 123-143. http://dx.doi.org/10.1177/1470595808091787

Trichter-Metcalf, L., \& Simon, T. (2002). Writing the mind alive. New York: Ballantine Books.

Vance, C. M., Groves, K. S., Gale, J., \& Hess, G. L. (2012). Would future entrepreneurs be better served by avoiding university business education? Examining the effect of higher education on business student thinking style. Journal of Entrepreneurship Education, 15, 127-141.

Ward, C., \& Kennedy, A. (1992). Locus of control, mood disturbance, and social difficulty during cross-cultural 
transitions. International Journal of Intercultural Relations, 16(2), 175-194. http://dx.doi.org/10.1016/0147-1767(92)90017-O

Ward, C., \& Kennedy, A. (1993). Psychological and socio-cultural adjustment during cross-cultural transitions: A comparison of secondary students overseas and at home. International Journal of Psychology, 28(2), 129-147. http://dx.doi.org/10.1080/00207599308247181

Ward, C., Bochner, S., \& Furnham, A. (2001). The psychology of culture shock. Hove: Routledge.

Weick, K. E. (1995). Sensemaking in organizations. Thousand Oaks: Sage.

Weick, K. E., \& Putnam, T. (2006). Organizing for mindfulness: Eastern wisdom and Western knowledge. Journal of Management Inquiry, 15(3), 275-287. http://dx.doi.org/10.1177/1056492606291202

World Economic Forum. (2011). Global talent risks report. Retrieved from http://www.weforum.org/reports/global-talent-risks-report-2011.

Zhou, Y., Jindal-Snape, D., Topping, K., \& Todman, J. (2008). Theoretical models of culture shock and adaptation in international students in higher education. Studies in Higher Education, 33(1), 63-75. http://dx.doi.org/10.1080/03075070701794833

\section{Copyrights}

Copyright for this article is retained by the author(s), with first publication rights granted to the journal.

This is an open-access article distributed under the terms and conditions of the Creative Commons Attribution license (http://creativecommons.org/licenses/by/3.0/). 